\title{
THE RELATIONSHIP BETWEEN WORKLOAD AND WORK STRESS IN NURSES IN THE EMERGENCY DEPARTMENT OF BAHTERAMAS GENERAL HOSPITAL IN SOUTHEAST SULAWESI PROVINCE
}

\author{
Noviati $^{1}{ }^{*}$, La Ode Kamalia $^{1}$, Sitti Marya Ulva ${ }^{1}$, La Ode Muhammad Yasmin ${ }^{1}$ \\ College of Health Sciences Waluya Mandala Kendari, \\ Southeast Sulawesi, Indonesia
}

* Correspondence

Noviati

Public Health Study Program, STIKES Mandala Waluya

Jl. Jend. AH. Nasution, Kambu, Kendari, Southeast Sulawesi

E-mail: noviati.novy@gmail.com,Phone:+6285255085235

\begin{abstract}
background:Workload is closely related to the productivity of health workers, which $53.2 \%$ of the truly productive time is spent on direct health services and the remaining $39.9 \%$ is used for supporting activities. Health workers, especially nurses, which the workload analysis can be seen from some aspects such as tasks based on their main function, additional works which are done, number of patients to be treated, work capacity according to the education he obtained, and working time to do the works. Excessive workload will lead to stress, which is usually dominated by somatic complaints, for example how a person's body responds when he is experiencing excessive workload.

Methods: This type of research is an analytic survey with cross sectional design that is a research design to determine the relationship of workload with work stress on nurses in Emergency Room Installation of Emergency Services Bahteramas General Hospital, Southeast Sulawesi Province, with a total sample of 38 respondents.

Results: The results obtained are significant $p=0,000<0.05$, with a Pearson Correlation value of 0.782 correlation, which means that the correlation is very strong, so it can be seen that there is a relationship between workload and work stress The amount of influence ( $r$ ) workload on stress, if calculated determinant coefficient $(R)$ or $(r) 2$, then $(0.782) 2 \times 100 \%=$ $61.2 \%$. This means that $61.2 \%$ workload contributes to the incidence of work stress. Conclusion: Based on the results obtained it can be concluded that there is a relationship between workload and work stress of nurses at IGD BLUD Bahteramas General Hospital in Southeast Sulawesi Province.
\end{abstract}

Keywords: Nurse, Workload, Work Stress

\section{INTRODUCTION}

The role of nurses is very important because as the spearhead in the Emergency Room (ER) and hospitalization, nursing is the longest power contact or interact with patients and families. This will lead to a strong stressor on nurses in the work 
environment. The duties and responsibilities of nurses is not a light thing to bear. The nurse responsible for the physical tasks, administrative agency where he works, dealing with anxiety, complaints and self-defense mechanisms of patients who appear on the patient due to the pain, tension, boredom in the face of patients with the condition suffering from critical illness or terminal state, on the other hand he should always be required to always appear as a good nurse profile by patients[1],

Stress is the body's response that are non-specific to any load demands it (psychosocial stressors). Symptoms of stress are dominated by somatic complaints, such as how to respond when a person's body is experiencing an excessive workload. If he could handle it means there is no interference with the function of organs, it is said to be concerned that does not experience stress. But otherwise if it turns out he has a defect of one or more organs of the body such that he can no longer perform the functions work well, then it is called experiencing distress[2], The situation of nurses in the ER stressful among others working to meet the needs of patients who are full of work where nurses do the work outside of the main job, inadequate preparation to face the emotional needs of patients and their families, the lack of support from the leadership, as well as the load overwork.

The workload is the number of activities that require expertise and must be done within a certain period in the form of physical and psychological[3], The workload is closely related to the productivity of health workers, of which $53.2 \%$ of the time actually used productively direct health services and the remaining $39.9 \%$ was used for support activities. Health workers, especially nurses, which analyzes the work load can be seen from aspects such as tasks that are run by the main function, as well as additional tasks are done, the number of patients who must be treated, capacity of works 
in accordance with the education he obtained, the working time which to do his work according to the working hours that take place every day, as well as the completeness of facilities that can help nurses complete its work well[4],

Results of research nurses workload based on the level of need for nurses in the ER Hospital Bahteramas Southeast Sulawesi province, the level of need for nurses pershif based method results treatment workshop, the number of nurses: Patient $=5: 9$ per shift, with three shifts per 24-hour thus the number of patients pershift an average of 15 people. Thus the need for nurses pershit 8 people, which means not in accordance with the number of nurses on duty in the ER General Hospital Bahteramas every shiftnya which amounted to only 6 people consisting of 2 nurses triage, 2 nurses nonsurgical and 2 surgical nurses. This causes excess workload of nurses experienced in dealing with patients.

In addition to serving a new patient, a nurse in the ER RSU Bahteramas also given the responsibility of caring for patients in the inpatient waiting room with a capacity 51 beds. This room can accommodate patients who have not entered the ward for the requested room is full. This causes the physical workload of nurses in the ER RSU Bahteramas in the weight category. The high number of patients entered the emergency room nurse on the other hand is required to work optimally and improve the quality of hospital services, the high demands of patients and families to nurse an example; family and patients demanding the healing of the disease, the ER nurse charged prepared with emergency and rapid response to changes in the patient's condition[5], 


\section{METHOD}

This research is an analytic survey with cross sectional design of the study is to determine the relationship of the workload with job stress in nurses in the Emergency Room (ER) BLUDs RSU Bahteramas Southeast Sulawesi Province. The population in this study were all nurses in the ER BLUDs RSU Bahteramas Southeast Sulawesi Province amounted to 38 people, so the sampling technique is total sampling, so the sample amounted to 38 people.

\section{RESULT}

Table 1.

Relations Workload And Nurses Job Stress The IGD RSU BLUDs Bahteramas Southeast Sulawesi Province

\begin{tabular}{|c|c|c|c|c|c|c|c|c|}
\hline \multirow{3}{*}{ Workload } & \multicolumn{6}{|c|}{ Work stress } & \multirow{2}{*}{\multicolumn{2}{|c|}{ amount }} \\
\hline & \multicolumn{2}{|c|}{ Weight } & \multicolumn{2}{|c|}{ moderate } & \multicolumn{2}{|c|}{ Light } & & \\
\hline & $\mathrm{n}$ & $\%$ & $\mathrm{n}$ & $\%$ & $\mathrm{n}$ & $\%$ & $\mathrm{n}$ & $\%$ \\
\hline Weight & 8 & 21.1 & 2 & 5.2 & 0 & 0 & 10 & 26.3 \\
\hline moderate & 3 & 7.9 & 24 & 63.2 & 0 & 0 & 27 & 71.1 \\
\hline Light & 0 & 0 & 0 & 0 & 1 & 2.6 & 1 & 2.6 \\
\hline Total & 11 & 29 & 26 & 68.4 & 1 & 2.6 & 38 & 100 \\
\hline
\end{tabular}

Table 2.

Pearson Product Moment Correlation Relationships Workload With Nurses Job Stress The IGD RSU BLUDs Bahteramas Southeast Sulawesi Province

\begin{tabular}{l|c|c|c} 
& $\mathrm{n}$ & $\begin{array}{c}\text { Pearson } \\
\text { Correlation }\end{array}$ & Sig. (2-tailed) \\
\hline $\begin{array}{l}\text { Workload and Stress } \\
\text { Relationship Work }\end{array}$ & 38 & 0,782 & 0000 \\
\hline
\end{tabular}

\section{DISSCUSION}

Based on the results of the Pearson product moment correlation between the SPSS system workloads of nurses in the ER stress BLUDs Bahteramas RSU obtained at 
0,782 . Obtained statistically significant test $p=0.000<0.05$. This shows the workload in BLUDs IGD RSU Bahteramas positively correlated with the stress of nurses, and correlation values obtained for 0,782 , which means a strong correlation. The amount of influence (r) workloads to stress, if the calculated determinant coefficient (R) or (r) 2, then $(0,782) 2 \times 100 \%=61.2 \%$. This means that the workload of $61.2 \%$ contributed to the incidence of occupational stress.

Based on the percentage of the workload of nurses workload obtained in the emergency room is largely the criteria being that as many as 27 respondents $(71.1 \%)$. It says the moderate category for nurses working diruangan filled with pressure and workload being the nurse should higher the level of work stress experienced by nurses where the workload was that not solved soon will add to the stress level of moderate itself as many patients who visit the emergency department, perform an act of observation the patient is left in the ER because wards are full, do documentation of the patient, delivering the patient in the room or in the investigation and do the work of the delegation of doctors to nurses so that the workload was that there were 26 respondents $(68.4 \%)$.

Heavy workload obtained 10 respondents $(26.3 \%)$ where nurses have a heavy work load in 1 shift work if there is a friend who is unable to go so as to provide a burden for friends who watch on the shift of the shift especially when the number of patients visiting in the emergency room, the patient's traffic accident that needs immediate attention, action observation monitor (blood pressure, pulse, temperature and elevation of the heart), observation of the drip and observations catheter to determine the production of fluid intake and discharge in the high care unit in because ICU and ICCU full,face relatives of patients with different character that trigger emotional that 
workload will increase the stressor is also high so of the heavy workload that there were 11 respondents (29\%) who experienced job stress severe form of saturation in the work, the response give up, drop out despair, withdrawal, touchy, irritable, decreased work productivity, leaving work.

Respondents to the work load lighter category No 1 respondent $(2.6 \%)$ had mild levels of stress levels as well as patients who visit the emergency room decreased, patients were observed using oral therapy, injections observation without infusion and serving administration since there are few nurses the airport administration emergency room because the cashier is available if it can not be present so that the nurse concurrently to become a cashier that of the light workload there is one respondent (2.6\%) experienced mild job stress. Stress experienced a sense of boredom will be job done, motivation and creativity of work are decreasing.

A relatively light workload is also due to the laziness factor ER nurse so that the nurse trying to get away from work to find a friend to interact or go in another room to interact with one another. Factors delay will be the presence of diruang IGD to do the job jg is one indication of the workload light for work that should be done as receiving patients, performing actions such as the installation of an intravenous infusion or observing the patient left behind as a result of treatment rooms full, documenting patient, making askep or move the patient to the treatment room or take to the investigations have been carried out by a friend of guard shift at the time.

The workload is felt the nurse ED is caused because in addition to the work that directly deal with patients also carry out activities not directly deal with patients, it is because there is no specialized personnel who commit acts of non nursing such as, 
cleaning medical instruments, making the beds of patients, the number of non-medical charge of delivering the patient to the room

As a result of the workload is too heavy can result in a worker suffering from disorders or occupational diseases. Excessive workload will cause either physical or mental fatigue and emotional reactions such as headaches, digestive disorders and irritable. While the workload is too little where the work is happening because of the repeated motion will lead to boredom, a sense of monotony. Boredom in routine daily work for assignments or work too little results in a lack of attention on the job so that potentially harmful to workers. Excessive workload or low can cause work stress.

These results are consistent with research conducted by Supardi[6], Which states that the workload affects the stress levels of nurses.

Based on research data obtained, in accordance with the concept that explains the positive relationship between the workload of nurses with work stress. With the creation of a balanced workload conditions and in accordance with the ability of nurses will generate positive attitude towards their work is done individually, it will be the achievement of the individual work performance [7].

\section{Conclusions}

Based on the analysis with a very strong correlation concluded that there is a correlation between workload and work stress of nurses in IGD RSU BLUDs Bahteramas Southeast Sulawesi Province.

It is expected that the head of Emergency Room (ER) BLUDs RSU Bahteramas in order to provide the workload on nurses should be appropriate to the capabilities, competence and professionalism, as well as proposing the addition of nurses so as not to cause the workload excessive for nurses that can cause stress and need to do more 
research on factor related to the workload and stress of nursesIGD RSU BLUDs Bahteramas Southeast Sulawesi Province.

\section{REFERENCES}

[1] Munir, "Roles and Responsibilities of Nurses," 2013.

[2] H. Dadang, Stress Management Anxiety and Depression, Jakarta: Balai Publisher FKUI 2008.

[3] DDR, "Effect of Job Stress, Workload Satisfaction," Journal of Psychology, University of the Holy Marya, pp. 1-10, 2010.

[4] Governor, "Factors associated with Workload nurse in Inpatient Unit RSJ Dadi Makassar," 2007.

[5] Anonymous, "IGD RSU Bahteramas," 2014.

[6] Supardi, "Job Stress Analysis on Conditions and Workload Nurses in," Thesis, 2007.

[7] Wibowo, "Relationships with Job Stress Workload Nurses," 2017. 